\title{
Flow cytometry based profiling of leukocytes: A new method for diagnosis of tropical theileriosis in crossbred cattle
}

\author{
Ramesh B. Jagtap ${ }^{1}$, Amit Gupta ${ }^{1}$ and Sushama R. Chaphalkar ${ }^{2}$
}

1. Department of Virology and Immunology, Vidya Pratishthan's School of Biotechnology, Baramati, Pune, Maharashtra, India; 2. Director, Vidya Pratishthan's School of Biotechnology, Baramati, Pune, Maharashtra, India.

Corresponding author: Ramesh B. Jagtap, e-mail: docrameshjagtap@gmail.com, AG: amitvsbt@gmail.com, SRC: director.vsbt@gmail.com

Received: 13-06-2015, Revised: 14-10-2015, Accepted: 25-10-2015, Published online: 11-12-2015

doi: 10.14202/vetworld.2015.1379-1385 How to cite this article: Jagtap RB, Gupta A, Chaphalkar SR (2015) Flow cytometry based profiling of leukocytes: A new method for diagnosis of tropical theileriosis in crossbred cattle, Veterinary World 8(12): 1379-1385.

\begin{abstract}
Aim: In India, dairy industries are important for the livelihood of small scale farmers and dairy owners. Tropical theileriosis, mostly affecting dairy cattle and buffaloes is a major threat to dairy and related industries. Tropical theileriosis is caused by Theileria annulata, a hemoprotozoan parasite transmitted by Ixodid ticks of Hyalomma spp. In the present study, we examined the clinical signs, hematological parameters and flow cytometric profile of whole blood in 30 theileriosis affected crossbred cattle. The aim of our study is to analyze, in comparison with clinical and hematological diagnosis, whether flow cytometry based profiling of leukocytes could be used as better, quick and alternative method for diagnosis and screening of bovine tropical theileriosis in crossbred cattle.
\end{abstract}

Materials and Methods: In this study, we screened parasites in 30 peripheral blood samples from clinical cases of theileriosis by Giemsa's staining technique in crossbred cattle. Hematological analysis was done to estimate hemoglobin (Hb) content, total red blood cell (RBC) count, total leukocyte count and differential leukocyte count. Further, flow cytometric analysis of whole blood was carried out to study leukocytes profile in affected cattle.

Results: Microscopic examination of stained blood films revealed the presence of piroplasms in erythrocytes and schizonts in lymphocytes. Hematological examination revealed significant $(\mathrm{p}<0.05)$ decrease of Hb percent $(\mathrm{Hb} \%)$, reduced total $\mathrm{RBC}$ and total leukocytes, lymphocytosis, eosinopenia, and neutropenia compared to that of apparently healthy cattle. Flow cytometric profiling of leukocytes revealed the severe effect on shape, size, and granularity of leukocytes, marked decrease in granulocytes and 3-5 fold increase in lymphocytes count compared to clinically healthy cattle. Thus, in both methods, namely conventional and flow cytometric analysis, marked lymphocytosis and decrease in other blood cell counts were observed compared to clinically healthy cattle.

Conclusions: From results, it can be concluded that though conventional staining techniques and hematology are efficient in diagnosis of theileriosis, leukocytes profiling based on flow cytometry combined with clinical examination could be a quick, novel and alternative method for diagnosis and screening of clinical tropical theileriosis in crossbred cattle. Thus, there is potential to offer a flow cytometry based diagnostic service for tropical theileriosis in crossbred cattle.

Keywords: clinical examination, flow cytometry, hematology, lymphocytosis, Theileria annulata.

\section{Introduction}

Tropical theileriosis is a tick-borne hemoprotozoan disease caused by a small irregular shaped hemoprotozoon parasite, Theileria annulata which is transmitted through bite of ticks of Hyalomma spp. It resulted in severe economic losses in tropical and subtropical countries and also drastically affects the immune status of animals [1]. Among confirmed cases, incidence reported was varying between $31 \%$ and $45 \%$ in crossbred cattle. The predominant clinical sign in affected animals are enlargement of superficial prescapular and prefemoral lymph nodes near tick infested site, high fever, pale or yellowish mucous membrane, anorexia, drop in milk production, straw colored urine, black feces, anemia, emaciation, prostration, etc. [2-4]. In severe cases diarrhea [5] and

Copyright: The authors. This article is an open access article licensed under the terms of the Creative Commons Attributin License (http:// creative commons.org/licenses/by/2.0) which permits unrestricted use, distribution and reproduction in any medium, provided the work is properly cited. even systemic signs like lateral recumbency was noted in certain cases [6]. After the bite of the tick, the sporozoites present in the gut are inoculated into the animal body. Infection thus initiated through the draining lymph node and sporozoites transform into schizonts in lymphocytes. Schizonts further transform into merozoites and infect erythrocytes of the host animal. This is followed by the development of piroplasms in erythrocytes which can be infective to ticks. The theilerial piroplasms in erythrocytes and schizonts stage in lymphocytes can be detected for diagnosis of disease.

Apart from the clinical symptoms, commonly used laboratory method for diagnosis is the detection of piroplasms in erythrocytes and Schizonts in lymphocytes by Giemsa's or Leishman's staining of thin blood films [1,4]. Further, diagnosis is supported by assessing the hematological parameters namely, hemoglobin percent $(\mathrm{Hb} \%)$, total erythrocyte count (TEC), total leukocyte count (TLC), differential leukocyte count (DLC), packed cell volume, mean 
corpuscular $\mathrm{Hb}(\mathrm{MCH}), \mathrm{MCH}$ concentration, etc. The available methods viz. microscopic examination of stained blood films for detection of parasites, analysis of hematological parameters for supportive diagnosis, possess certain limitations and pitfalls. Rapid, reproducible, sensitive, high throughput method for diagnosis and screening of theileriosis from field samples in cattle is lacking.

Flow cytometry is a powerful tool for enumeration of lymphocyte subpopulations in peripheral blood, characterization of the composition of complex cell populations involved in clinical disorders, immunophenotyping [7], cross-matching of tissues in organ transplantation and characterization of lymphomas and leukemias, etc. In comparison with traditional methods, flow cytometry based assays are more rapid, quantitative, and precise and can be used for diagnosis of various clinical disorders. Flow cytometry has emerged as one of the new technologies in veterinary clinical laboratories for diagnosis of various disorders [7-11].

Thus, our study aimed to clinically examine suspected animals for theileriosis, its supportive diagnosis through microscopic examination of stained blood films, hematology and further to develop flow cytometry based assay for diagnosis and screening of suspected field samples for theileriosis in crossbred cattle.

\section{Materials and Methods}

Ethical approval

This work was approved by Institute Animal Ethical Committee (IAEC), under the component Animal disease Surveillance of "Biovillage" scheme of Vidya Pratishthan's School of Biotechnology, Baramati, India.

\section{Clinical examination of suspected animals}

The Holstein Friesian crossbred cattle aged between 3 and 5 years suspected for theileriosis were examined thoroughly for clinical signs and symptoms. The animals with high fever above $104^{\circ} \mathrm{F}$ are examined further whether there is enlargement of prescapular lymph nodes, color of feces and urine, breathing difficulties, feeding behavior, corneal opacity and emaciation.

\section{Sample collection}

About $5 \mathrm{ml}$ of blood in ethylenediaminetetraacetic acid (EDTA) coated tubes was collected from crossbred cattle suspected for theileriosis from Baramati area of western Maharashtra, India. A total of 40 blood samples from lactating cattle aged between 3 and 6 years were collected and used for hematological and flow cytometric analysis. Blood smears were prepared from fresh blood immediately after collection. Crossbred cows were grouped into an infected group $(\mathrm{n}=30)$ showing clinical signs viz. high fever, enlarged peripheral lymph nodes, $\geq 4 \%$ parasitemia by microscopic examination and clinically healthy crossbred cows $(\mathrm{n}=10)$ with no visible clinical signs and no parasitemia in erythrocytes or lymphocytes by microscopic examination of stained blood films.

\section{Hematological examination}

The TEC was performed by a manual method using hemocytometer and diluting fluid as saline. The TLC was performed using improved Neubauer hemocytometer and white blood cells diluting fluid. Cyanomet $\mathrm{Hb}$ method was used for the estimation of $\mathrm{Hb}(\mathrm{g} / \mathrm{dl})$. Thin blood smears were prepared from the fresh peripheral blood and stained by Giemsa's stain. Further, DLC was performed by manual method as per Feldman et al. [12].

\section{Flow cytometric analysis}

Blood $(5 \mathrm{ml})$ samples from clinically healthy and theileriosis suspected cattle were collected in EDTAcoated vacutainers. To study the differential profiling of leukocytes, briefly, $100 \mu 1$ of whole blood of clinically healthy as well as infected cattle was lysed with lysis buffer $\left(155.5 \mathrm{mM}, \mathrm{NH}_{4} \mathrm{Cl}, 1 \mathrm{mM} \mathrm{NaHCO}\right.$ and $0.109 \mathrm{mM}$ EDTA-Na $\mathrm{N}_{3}$ ). After addition of lysis, buffer samples were incubated for $15 \mathrm{~min}$ at room temperature in the dark. The samples were then centrifuged at $\times 300 \mathrm{~g}$ for $15 \mathrm{~min}$ at $4^{\circ} \mathrm{C}$, and the cells washed two times with phosphate-buffered saline (PBS) and finally resuspended in $1 \mathrm{ml}$ of PBS. The normal as well as infected samples of theileriosis were kept in ice cold and dark during the whole procedure as well as during storage before analysis. The flow cytometric samples were analyzed within $24 \mathrm{~h}$ in an FACS calibur flow cytometer (Becton Dickinson). The flow cytometer was equipped with a $488 \mathrm{~nm}$ argon laser and Cell Quest TM Software (Becton Dickinson). 10,000 events were collected from each sample. The leukocyte subpopulations, monocytes and granulocytes, were identified by their forward as well as side scatter characteristics, enclosed in electronic gates, and separately analyzed for fluorescence intensity. The results were calculated as the percent gated cells of 10,000 events. A brief flow chart of flow cytometry based profiling of leukocytes in whole blood of cattle was showed in Figure-1.

\section{Statistical analysis}

To determine the statistical significance among different variables, means of hematological parameters were compared using SPSS program (Statistical Program for Social Sciences) version 17. One-way ANOVA was used for comparison between two groups (clinically healthy control and diseased cattle). All hematological values were expressed as mean and standard error of mean and $p<0.05$ was considered as statistically significant.

\section{Results and Discussion}

In India, rearing of crossbred cattle is economically beneficial and important to farmers because of its high milk production capacity than indigenous cattle that is depicted in the recent share of milk production 
of crossbred cattle which is more than half of total cattle milk production [13]. The major disadvantage in rearing crossbred and exotic cows is poor adaptability to environmental and feeding conditions than indigenous breeds and thus crossbred cattle could be more prone to diseases especially hemoprotozoan diseases (theileriosis) because of the presence of more exotic blood [14]. Our group focused on mostly HF cross, or Jersey crossbred animals reared in Baramati area of Maharashtra, India. In the past few decades, cases of bovine tropical theileriosis were reported frequently in India [15-17], especially in Maharashtra [18]. Preventive measures such as the development of vaccines against theileriosis in India were reported previously $[19,20]$. The currently available licensed vaccine for theileriosis in India is Rakshavac-T (Indian Immunologicals Pvt. 1td.) which is recommended for prophylactic vaccination against $T$. annulata in crossbred and exotic cattle. Though treatment with oxytetracycline and buparvaquone were curative in most instances, still better curative and preventive measures are needed for the control of the disease. In field conditions diagnosis of theileriosis is carried out by submitting the peripheral blood samples collected at height of temperature to nearby veterinary diagnostic laboratory and detection of parasites in Giemsa or Leishman stained blood smear. Further, diagnosis is supported by analysis of hematological parameters in suspected cases. Our group focused on clinical examination of suspected cases, detection of parasites in Giemsa stained blood films, hematological analysis and further flow cytometric analysis of whole blood to profile leukocytes compared to clinically healthy cattle.
The clinical examination (Table-1) showed that most of the animals were with high fever (100\%). Enlargement of prescapular and poplitial lymph nodes $(90.00 \%)$, anorexia in few cases, labored breathing in $60 \%$ of cases, red-coffee colored urine and even dark feces were noted in few cases. Anorexia was less prominent in most of the cases, as the most of cows slowly fed than healthy cows. In certain previous reports [21] of clinical examination of theileriosis infected cattle showed similar but less severe signs, i.e., $18.51 \%$ cases of swelling of lymph nodes and hematuria, but anorexia reported was higher $(42.62 \%$ cases), pale mucous membrane in the most of cases $(42.59 \%)$ and conjunctivitis in few cases $(29.62 \%)$. Similar findings were reported by Sandhu et al. [22]

Table-1: Clinical and microscopic findings among theileriosis suspected crossbred cattle.

\begin{tabular}{lcc}
\hline Clinical sign & \multicolumn{2}{c}{ Infected cattle } \\
\cline { 2 - 3 } & $\begin{array}{c}\text { Total } \\
\text { number (30) }\end{array}$ & Percentage \\
\hline Fever (above 104' ${ }^{\circ}$ ) & 30 & 100 \\
Enlargement of & 27 & 90.00 \\
prescapular and & & \\
prefemoral lymph nodes & 18 & 60.00 \\
Anorexia & 20 & 66.67 \\
Pale mucous membrane & 18 & 60.00 \\
Respiratory signs & 12 & 40.00 \\
Straw reddish urine & 18 & 60.00 \\
Emaciation & 4 & 13.33 \\
Corneal opacity & 10 & 33.33 \\
Dark feces & 26 & 86.67 \\
Piroplasms in RBC's & 22 & 73.33 \\
Schizont's in WBC's &
\end{tabular}

$\mathrm{RBC}=$ Red blood cells, $\mathrm{WBC}=$ White blood cell

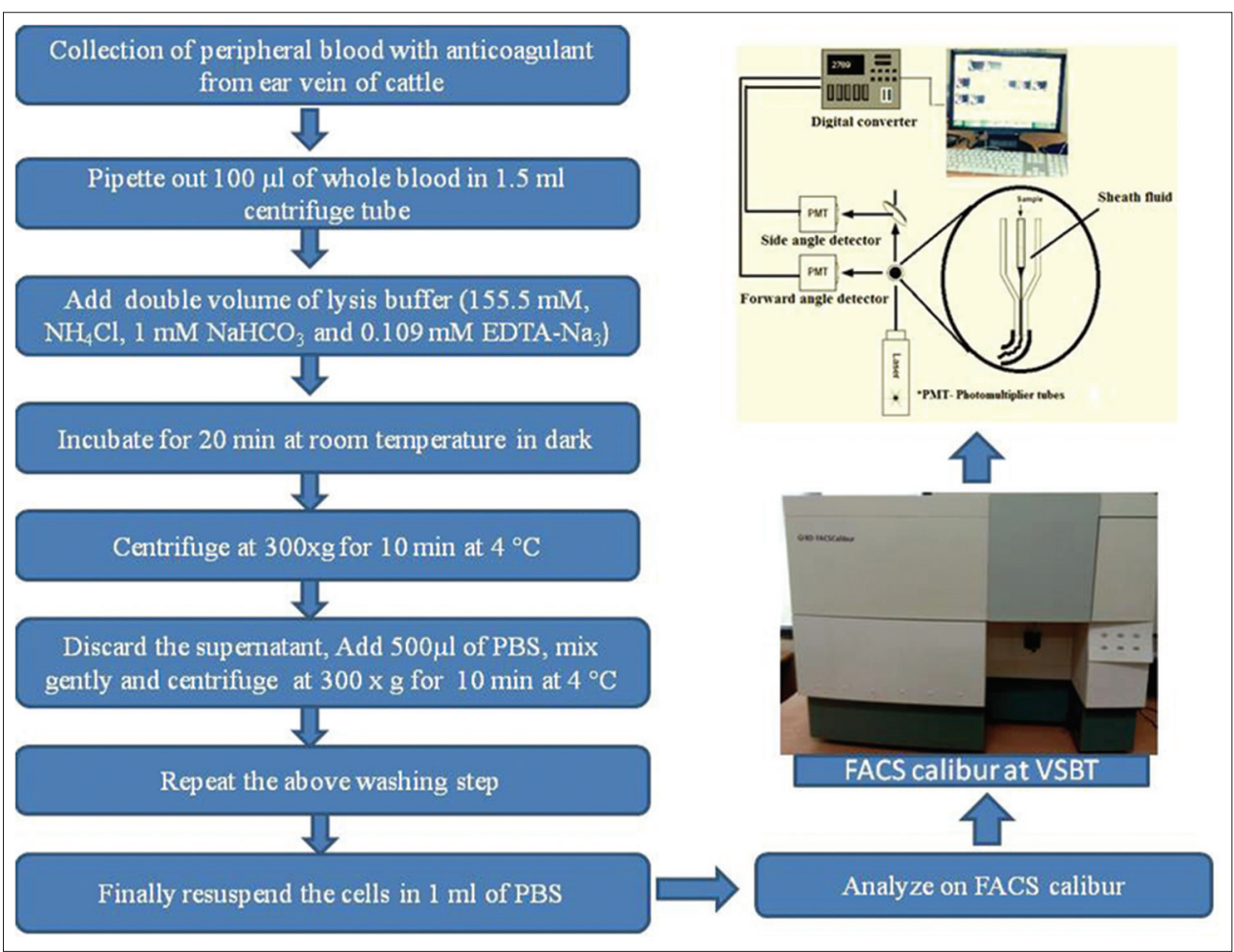

Figure-1: Flow chart of flow cytometry based profiling of leukocytes from whole blood of cattle. 
and Radostits et al. [23]. Anorexia could be attributed to persistent fever and in the early stage of the disease hyperplasia of lymphoid tissues could led to the enlargement of superficial lymph nodes. The corneal opacity may be the result of white blood cells infiltration. As anemia is one of the pathognomic signs of the disease, decreased TEC and hemoglobin concentration was observed in infected cattle compared to clinically healthy cattle. Microscopic examination of stained blood films revealed the presence of piroplasms in erythrocytes (86\%) (Figure-2) and Schizont's in lymphocytes $(73.33 \%)$. However, Al-Emarah et al. [24] reported $69.43 \%$ and $25.43 \%$ erythrocyte as well as lymphocytic stage of T. annulata parasites while both stages in 5.26\% cases in naturally infected cattle. Erythrocytic and lymphocytic stages of parasites in cattle, buffaloes, and horses were reported previously with variation in the percentage of occurrence [25-28].

Hematological examination (Table-2) revealed that there is significant decrease of $\mathrm{Hb}$ to an average of $5.84 \pm 0.85 \mathrm{~g} / \mathrm{dl}$, TLC $\left(10^{3} / \mu \mathrm{l}\right)$ was decreased to $5.56 \pm 0.58$ and TEC $\left(10^{6} / \mu \mathrm{l}\right)$ was decreased to $5.24 \pm 0.65$ compared to clinically healthy cattle. DLC revealed eosinopenia, lymphocytosis $(83 \%$ of cases) associated with Neutropenia and $10 \%$ of cases (Table-2) showed lymphocytopenia associated with Neutrophilia and insignificant increase in monocytes count in few cases, in which slight decreased lymphocyte count was observed. There is slight variation compared to previous reports of theileriosis, in which mostly lymphocytopenia is reported [18,26,29] but lymphocytosis was also reported previously by certain researchers [4]. It was observed that in neutropenia

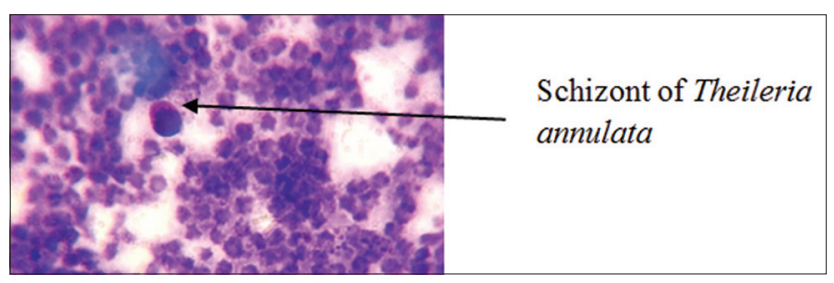

Figure-2: Schizonts of Theileria annulata in lymphocytes of infected cattle (Giemsa stain; oil immersion).

Table-2: Hematological parameters in normal and infected cattle.

\begin{tabular}{lcc}
\hline Parameters & $\begin{array}{c}\text { Clinically } \\
\text { healthy } \\
\text { cattle }(\mathbf{n = 1 0})\end{array}$ & $\begin{array}{c}\text { Clinical } \\
\text { theileriosis } \\
(\mathbf{n = 3 0 )}\end{array}$ \\
\hline RBCs $\left(10^{6} / \mu \mathrm{l}\right)$ & $7.91 \pm 1.03^{\mathrm{a}}$ & $5.24 \pm 0.65^{\mathrm{b}}$ \\
$\mathrm{Hb}(\mathrm{g} / \mathrm{dl})$ & $11.96 \pm 3.23^{\mathrm{a}}$ & $5.84 \pm 0.85^{\mathrm{b}}$ \\
$\mathrm{TLC}\left(10^{3} / \mu \mathrm{l}\right)$ & $8.10 \pm 0.22^{\mathrm{a}}$ & $5.56 \pm 0.58^{\mathrm{b}}$ \\
Neutrophils $\left(10^{3} / \mu \mathrm{l}\right)$ & $3.26 \pm 0.43^{\mathrm{a}}$ & $2.14 \pm 0.26^{\mathrm{b}}$ \\
Lymphocytes $\left(10^{3} / \mu \mathrm{l}\right)$ & $5.02 \pm 0.26^{\mathrm{a}}$ & $7.085 \pm 0.64^{\mathrm{b}}$ \\
Eosinophils $\left(10^{3} / \mu \mathrm{l}\right)$ & $0.42 \pm 0.034^{\mathrm{a}}$ & $0.31 \pm 0.009^{\mathrm{b}}$ \\
Basophils $\left(10^{3} / \mu \mathrm{l}\right)$ & $0.023 \pm 0.006$ & $0.018 \pm 0.006$ \\
Monocytes $\left(10^{3} / \mu \mathrm{l}\right)$ & $0.321 \pm 0.016$ & $0.350 \pm 0.022$ \\
\hline
\end{tabular}

Means bearing different superscripts differ significantly along column at $p<0.05$, one-way $A N O V A, R B C=$ Red blood cells, $\mathrm{Hb}=$ Hemoglobin, $\mathrm{TLC}=$ Total leukocyte count cases; there is mostly increase in lymphocyte count and vice versa in remaining cases. Hence, neutropenia and lymphocytosis observed could be relative in those instances.

Flow cytometry is generally used for elucidating the structural and functional properties viz. shape, size, granularity, etc. of the cell suspended in a stream of fluid as they pass through laser light either one, two or three. Further, the flow cytometer is used for differential enumeration of peripheral blood cells, cross-matching of tissues in organ transplantation and characterization of lymphomas and leukemias, immunophenotyping, i.e., detection of cell surface markers viz. cluster of differentiation; cell cycle analysis for apoptosis of cells, viability studies, estimation of total proteins, enzyme activity, gene expression analysis, etc., $[30,31]$. Number, shape, size and granularity of the cells in the fluid are estimated through forward and side scatter of the instrument. Light scatter properties reveals that there is a direct relationship between forward scattered light and cell volume, and this property of light is utilized in flow cytometry. The scattering of light i.e., coherent light source $(488 \mathrm{~nm}$, blue) using forward scatter (small angle scattering between $0.5^{\circ} \mathrm{C}$ and $5^{\circ} \mathrm{C}$ ) measures shape and size of the cell and side scatter (large angle scattering between $15^{\circ} \mathrm{C}$ and $150^{\circ} \mathrm{C}$ dark field) measures complexity and granularity of the cell. The FACS can be used to measure the live cells and dead cells in the form of forward and side scatter; dead cells are more in side scatter and lower in forward scatter, whereas it is vice-versa for live cells [32-34].

As showed in scatter diagram (Figure-3), the profiling of leukocytes by flow cytometer revealed that T. annulata affects severely shape, size and granularity of peripheral blood leukocytes. Granulocyte count was decreased sharply averaging $52.64 \pm 5.26 \%$ of 30 cases studied compared to clinically healthy cattle (Figure-4). Further, it was found that there was 3-5 fold increase in lymphocyte count in theileriosis suspected cases compared to clinically healthy crossbred cattle. Hematological and flow cytometric analysis showed a significant decrease in TLC (leukogram), eosinophils and neutrophils while lymphocytes showed a significant increase in comparison with clinically healthy control animals. The continuous harmful effects of toxic metabolites of Theileria spp. on the hematopoietic organs, especially bone marrow and their interference with the process of leucogenesis could be responsible for changes in leukocytes count. In response to entry or invasion of Theileria parasites, lymphocytes or monocytes count could show relative increased value. Lamia [35] reported similar findings in Theileria infected cattle. Significant neutropenia, decreased TLC and TEC could be due to breakdown of red blood cells by Theileria spp. or its toxic metabolites, which further could led to stimulation of the phagocytosis by lymphocytes and monocytes to remove fragmented and dead cell debris and toxic remnants of ruptured red 


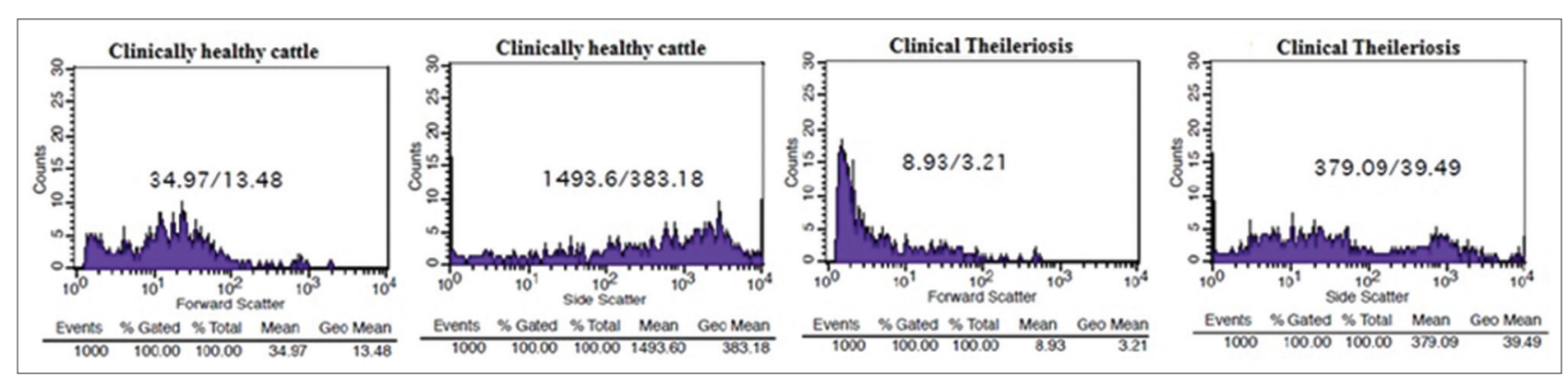

Figure-3: Flow cytometric analysis of clinically healthy and theileriosis infected crossbred cattle using forward (shape and size) and side scatter (granularity) to estimate the counts.
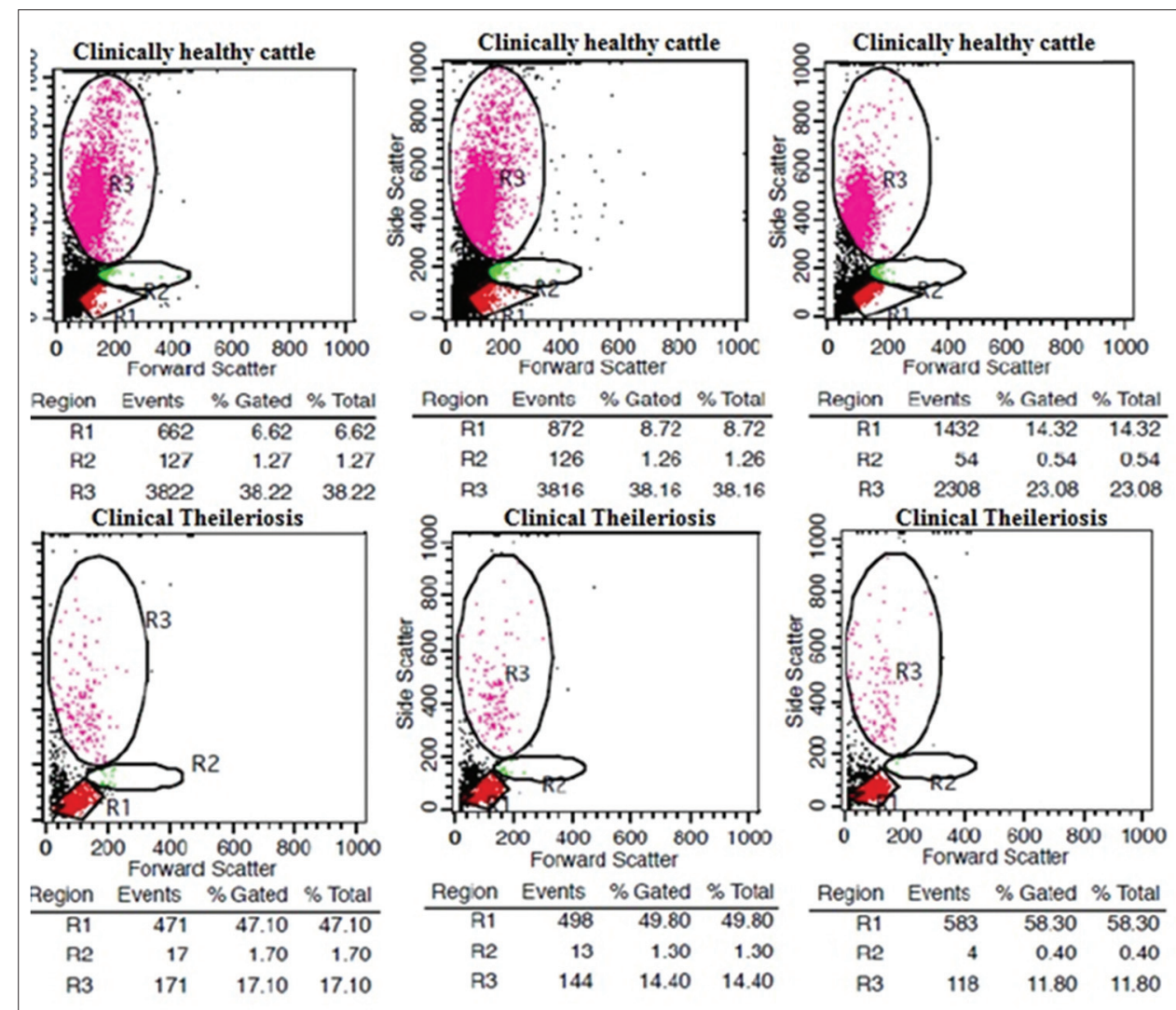

Figure-4: Flow cytometric analysis of clinically healthy and theileriosis infected crossbred cattle to estimate the lymphocytes, monocytes, and granulocytes count: Decrease in granulocyte count and marked lymphocytosis in infected cattle compared to clinically healthy cattle.

blood cells. Which further increase the tissue demand of neutrophils that led to a reduction of neutrophils in peripheral blood circulation. Similar findings viz. red cell destruction, decreased TEC, TLC were reported previously in cattle $[2,36]$.

\section{Conclusions}

Thus, this study revealed that there is preliminary evidence of the prevalence of bovine tropical theileriosis in Baramati taluka of western Maharashtra. The diagnosis and screening of bovine tropical theileriosis can be done with conventional staining techniques and hematology. However, leukocytes profiling based on flow cytometry combined with clinical examination could be a quick, novel and alternative tool for diagnosis and screening of clinical tropical theileriosis in crossbred cattle and thus, there is potential to offer flow cytometry based diagnostic service for tropical theileriosis in crossbred cattle. Further studies could be done to develop more sensitive and accurate flow cytometric assay for other hemoprotozoan diseases viz. babesiosis, anaplasmosis in cattle and small ruminants.

\section{Authors' Contributions}

The study was designed, and protocols were carried out by RBJ. Sample collection as Veterinarian and further manuscript was written by RBJ. The FACS machine was operated by AG and overall approval by director, SRC. All authors have read and approved the final version of the manuscript.

\section{Acknowledgments}

The authors are thankful to Vidya Pratishthan and especially to "Biovillage" Scheme of Vidya 
Pratishthan's School of Biotechnology (VSBT), funded by Dept. of Rev.GOI (Under 35 AC independent donors).

\section{Competing Interests} interests.

The authors declare that they have no competing

\section{References}

1. Urquhart, G., Armour, J., Duncan, J., Dunn, A. and Jennings, F. (1996) Veterinary Parasitology. $2^{\text {nd }}$ ed. Blackwell Science Ltd., USA.

2. Ali, A.T., Ehsan, H. and Bahrami, A.M. (2013) Biochemical, hematological studies in cattle naturally infected with Theileria annulata. Bull. Environ. Pharmacol. Life Sci., 2(9): 07-10.

3. Ganga, N., Ananda, K.J. and Kavitha Rani, B. (2010) Theileriosis in calves and its successful treatment. Vet. World, 3(4): 19.

4. Hussein, A.H., Mohammed, N.A.E.S. and Mohammed, H.K. (2007) Theileriosis and babesiosis in cattle: Haemogram and some biochemical parameters. ISAH-2007 Tartu, Estonia. p143-150.

5. Radostits, O., Gay, C., Blood, D. and Hinchcliff, K. (2000) Veterinary Medicine. $9^{\text {th }}$ ed. Blaillier, London, Philadelphia, New York

6. Stockham, S., Kjemtrup, A., Conrad, P., Schmit, D., Scott, M., Robinson, T., Tyler, J., Jonson, G., Carson, C. and Cuddihee, P. (2000) Theileriosis in a Missouri beef herd caused by Theileria buffeli: Case report, herd investigation, ultrastructure, phylogenetic analysis, and experimental transmission. Vet. Pathol., 37: 11-21.

7. Guzera, M., Cian, F., Leo, C., Winnicka, A. and Archer, J. (2014) The use of flow cytometry for immunophenotyping lymphoproliferative disorders in cats: A retrospective study of 19 cases. Vet. Comp. Oncol.,10:1-12.

8. Goto-Koshino, Y., Ohno, K., Nakajima, M., Mochizuki, H., Kanemoto, H. and Tsujimoto, H. (2011) A rapid and simple method to obtain canine peripheral blood-derived macrophages. J. Vet. Med. Sci., 73: 773-778.

9. Tarrant, J.M. (2005) The role of flow cytometry in companion animal diagnostic medicine. Vet. J., 170: 278-288.

10. Thomason, J., Archer, T., Mackin, A., Stokes, J. and Pinchuk, L. (2014) Applications of flow cytometry in veterinary research and small animal clinical practice. J. Vet. Med. Res., 1(1): 1004.

11. Yong, H.P., Yi, S.J., Joo, Y.P., Jin, S.M., So, H.K., Nam, H.K., Jong, S.A., William, C.D. and Christopher, J.D. (2004) Characterization of lymphocyte subpopulations and major histocompatibility complex haplotypes of mastitis-resistant and susceptible cows. J. Vet. Sci., 1: 29-39.

12. Feldman, B.F., Zinkl, J.G. and Jain, N.C. (2000) Schalm's Veterinary Haematology. $5^{\text {th }}$ ed. Lippincott Williams and Wilkins, A Wolters Kluwer Company, Philadelphia, USA.

13. BAHS. (2012) Basic Animal Husbandry Statistics. Government of India, Ministry of Agriculture, Department of Animal Husbandry, Dairying and Fishries, Krishi Bhawan, New Delhi.

14. Rup, R., Gupta, S.K. and Sangwan, A.K. (2004) Comparative infection rates of Theileria annulata - in Hyalomma anatolicum anatolicum ticks in arid and semi arid regions of North West India. J. Vet. Parasitol., 18(2): 109-114.

15. Ananda, K.J., D'Souza, P.E. and Puttalakshmamma, G.C. (2009) Prevalence of haemoprotozoan diseases in crossbred cattle in Bangalore North. Vet. World, 2(1): 15-16.

16. Vahora, S.P., Patel, J.V., Parel, B.B., Patel, S.B. and Umale, R.H. (2012) Seasonal incidence of haemoprotozoan diseases in Kaira and Anand district of Gujarat, India. Vet. World, 5(4): 223-225.

17. Mahajan, V., Gupta, M.P., Bal, M.S., Kumar, H.,
Mittal, D., Filia, G., Sharma, S., Banga, H.S., Kaur, K., Singla, L.D., Verma, S., Vasudev, A. and Sandhu, K.S. (2013) Outbreaks of theileriosis in cattle in Punjab. Indian Vet. J., 90: 77-78.

18. Ugalmugle, S.S., Jayraw, A.K. and Gatne, M.L. (2010) Prevalence and clinical pathology of bovine tropical theileriosis in cross-bred population of Ahmednagar district of Maharashtra. J. Vet. Parasitol., 24(2): 141-145.

19. Sharma, R.D. and Nichani, A.K. (1990) A cell culture vaccine against bovine tropical theileriosis even in for young calves. Proceeding first Asian Congress of Veterinary Parasitology, Bihar Veterinary College, Patna, India.

20. Grewal, A.S. (1992) Development of theilaria vaccine for control of bovine tropical theileriosis. Proceeding Annual Scientist meet of All India Coordinated Research Projects on 'Intracellular Blood Protista with Special Reference to the Immune-Prophylaxis and Control' at Haryana Agricultural University, Hisar, India.

21. Ibrahim, A.K., ElBehairy, M.K.A. and Awad, W.S. (2009) Clinical and laboratory diagnosis of piroplasmids in naturally infected cattle in Egypt. J. Egypt. Vet. Med. Assoc., 69(2): 197-209.

22. Sandhu, G.S., Grewal, A.S., Singh, A., Kondal, J.K., Singh, J. and Brar, R.S. (1998) Haematological and biochemical studies on experimental Theileria annulata infection in crossbred calves. Vet. Res. Commun., 22: $347-354$

23. Radostits, O.M., Gay, C.C., Blood, D.C. and Hinchliff, K.W. (2000) Caudal vena caval thrombosis and embolicpneumonia in cattle (posterior vena caval thrombosis, PVCT). In: Veterinary Medicine. A Textbook of the Diseases of Cattle, Sheep, Pigs, Goats and Horses. $9^{\text {th }}$ ed. W. B. Saunders, London. p451-452.

24. Al-Emarah, G.Y.A., Khudor, M.H. and Daham, H.R. (2012) Clinical, haematological and biochemical study to cattle naturally infected with Theileria annulata in north of Basrah province; AL-Qadisiya. J. Vet. Med. Sci. 11(1): 54-62.

25. Fayez, A.S., Youssef, R.R., Rizk, L.G. and Said, S.F. (2013) Epidemiology, diagnosis and therapy of Theileria equi infection in Giza, Egypt. Vet. World, 6(2): 76-82.

26. Ghanema, M.M., Abdelhamidb, O.M. and Bakir, N.M.A. (2013) Clinico-Biochemical, serological and molecular study on tropical Theileriosis in Egyptian water buffaloes (Bubalus Bubalis). Alex. J. Vet. Sci.; 39: 1-11.

27. Kohli, S., Atheya, U.K. and Thapliya, A. (2014) Prevalence of theileriosis in cross-bred cattle: Its detection through blood smear examination and polymerase chain reaction in Dehradun district, Uttarakhand, India. Vet. World, 7(3): 168-171.

28. Salib, F.A., Raouf, R.Y., Laila, G.R., Samer, F.S., (2013) Epidemiology, diagnosis and therapy of Theileria equi infection in Giza, Egypt, Vet. World:76-82.

29. Ramazan, C. and Ugur, U. (2006) Haematological and coagulation profiles during severe tropical theileriosis in cattle. Turk. J. Vet. Anim. Sci., 30: 577-582.

30. Gupta, A., Jagtap, R.B. and Chaphalkar, S.R. (2014) Antiviral activity of Azadirachta indica leaves against Newcastle disease virus: A study by in vitro and in vivo immunological approach. Int. J. Curr. Pharm. Res., 2(6): 715-722.

31. Murphy, R.W., Lowcock, L.A., Smith, C., Darevsky, I.S., Orlov, N. and MacCulloch, R.D. (1997) Flow cytometry in biodiversity surveys: methods, utility and constraints. Amphibia-Reptilia., 18: 1-13, 17.

32. Gupta, A., Khajuria, A., Singh, J. and Suri, K.A. (2015) Adjuvant effect of biopolymeric fraction from Picrorhiza kurroa to promote both Th1 and Th2 immune responses. $J$. Prog. Res. Biol., 1(1): 7-16.

33. Lo, K., Brinkman, R.R. and Gottardo, R. (2008) Automated gating of flow cytometry data via robust model-based clustering. Cytometry A, 73(4): 321-332.

34. Reardon, A.J.F., Elliott, J.A.W. and McGann, L.E. (2014) Fluorescence as an alternative to light-scatter gating 
strategies to identify frozen-thawed cells with flow cytometry. Cryobiology, 69(1): 91-99.

35. Abou-El Hassan, L. A. M. (1997) Clinico-pathological study of Theileriosis in New valley. M.V. Sc. Thesis, Department of Animal Pathology and Clinical
Pathology, Faculty of Veterinary Medicine, Assiut University, Egypt.

36. World Organisation for Animal Health. (2008) Manual of Diagnostic Tests and Vaccines for Terrestrial Animals. OIE, Paris.

$* * * * * * * *$ 